\title{
Optic Neuritis and Multiple Sclerosis
}

\author{
G.C. Ebers and T.E. Feasby
}

The relationship of idiopathic optic neuritis $(\mathrm{ON})$ to multiple sclerosis (MS) and the frequency with which ON evolves into MS has been a perennially debated issue. A close relationship is clear since many patients with clinically definite MS have ON at some point in the course of their disease. Furthermore patients with ON commonly go on to develop clinically definite MS in follow-up. However, there is still dispute over the frequency of this evolution and figures ranging from $13 \%$ to $85 \%$ have been reported in the literature (McAlpine 1964; Kurland et al 1966). The studies with the lowest conversion figures would appear to be the best in terms of duration of follow-up. Accordingly, isolated ON has enjoyed a diagnostic status approaching that of a specific disease and evidence has been reported to support this view. The alternative viewpoint is that $\mathrm{ON}$ represents an intermediate form of demyelinating process but differs genetically and immunologically from MS. Evidence to support this includes histocompatibility data as well as differences in immune response among ON patients, MS patients, and controls (Arnason et al 1973; Compston et al 1978; Sandberg Wolheim et al 1975; Ebers \& Paty 1979).

All the above evidence must be considered in light of the fact that isolated ON has yet to be established as a clinicopathological entity. That a demyelinative plaque can remain solitary is suggested by our own material which includes a case in which only a single typical plaque was found at autopsy (lumbar cord) despite careful neuropathological examination (Dr. J. Gilbert). The history was of gradually progressive paraparesis for more than a decade and oligocional banding was present in the spinal fluid.

At the same end of an apparent continuum are patients with incidental MS found at autopsy (Georgi 1961; Gilbert and Sadler 1983). There do appear to be patients who, despite prolonged follow-up, do not develop evidence of dissemination either by clinical or laboratory criteria (Ebers et al 1981). Given that demyelination may be unifocal for the life of the patient, how often does this occur in those with ON?

There are a number of problems in evaluating the rate of conversion of $\mathrm{ON}$ to MS. To some extent the varying conversion rates are understandable and reflect the nature of ascertainment, the care with which cases already having MS are excluded, the type of follow-up and other unknown factors. The duration of follow-up is a most important factor. Although most patients who develop MS do so within five years (Ebers et al 1981), there has been a report of an individual in whom a fifty-six year interval elapsed between the diagnosis of $\mathrm{ON}$ and subsequent evidence of dissemina- tion (Perkin \& Rose 1979). Recent studies have strengthened the relationship between isolated ON and MS. Patients with ON in the distant past (with normal CSF and evoked response) can be found in the families of patients with MS, suggesting a very close association between even the isolated form of the disease and MS. (Ebers et al 1981).

The low figures on conversion in two of the studies having the longest follow-up do not support the view that most if not all cases of demyelinative $\mathrm{ON}$ are early formes frustes of MS.

In our center, prospectively collected data have led us to believe that more than half the patients presenting with clinically isolated $\mathrm{ON}$, will go on to develop MS, particularly those who show oligoclonal banding in the CSF (Feasby \& Ebers 1982; Moulin et al 1983). It is conceivable that this reflects factors peculiar to high risk areas such as ours. Poskanzer (1980) has remarked on the rarity of isolated $\mathrm{ON}$ in the very high prevalence region of Shetland-Orkney. However, some studies have not shown any regional variation in risk (Kurland et al 1966; Kahana et al 1966).

Another possible consideration is that some of the early studies showing very low conversion rates included cases which did not have ON. One condition which can simulate ON and cause diagnostic confusion is central serous retinopathy (CSR) (Kraushar and Miller 1982). The similarities to idiopathic $\mathrm{ON}$ are sometimes striking. Typically, CSR occurs in young adults, commonly under stress, has a seasonal predilection, is unilateral, produces visual blurring and a relative central scotoma, improves spontaneously, but may recur. The visual impairment in such patients is often correctable. Diagnosis is usually apparent when loss or alterations of the foveal reflex is present. Patients may demonstrate distortions of vision when they view an Amsler grid consisting of numerous small adjacent open squares. Fluorescein angiography demonstrates macular leaking of dye. Color vision and pupillary light reactions are typically preserved. The pathogenesis of the condition is uncertain.

A final point of possible relevance to the large ON studies in veterans, (Kurland et al 1966) is that in CSR, males predominate in the ratio of 10 to 1 , (the veterans' ON study was composed entirely of males). The other low conversion rate study gives an MS-like sex ratio (Percy and Nobrega 1972). Exclusions from the veterans' data are listed, but the entity of CSR is not specifically mentioned although other retinal disorders were recognized. Although CSR is not a rare condition, it has been difficult to establish prevalence rates. There is evidence that ON and CSR have similar 
prevalence both at our hospital and elsewhere (C. Canny and D. Gass personal communications). Information on the frequency of color vision defects and afferent pupillary changes in the early studies showing low rates of conversion would help eliminate or include this possibility. Inclusion of non-demyelinative $\mathrm{ON}$ in some series might explain the intermediate position of $\mathrm{ON}$ in some studies of histocompatibility antigens and immunological parameters. If the immune abnormalities are secondary, similar results could be expected. Could the lower rate of conversion in men that has been reported reflect the inclusion of CSR cases? An indication that retinal disorders may simulate $\mathrm{ON}$, particularly in neurologic series, is found in the excellent study of ON prognosis by Cohen et al (1979). To define a study population of 76 cases of $\mathrm{ON}, 254$ individuals with disorders originally considered compatible with the diagnosis of $\mathrm{ON}$ had to be excluded. Retinal choroidal lesions accounted for 46 of these. Although an ON-MS conversion rate of only $28 \%$ was reported, closer examination of the data reveals an additional $7 \%$ with probable or possible MS and further patients with recurrent $\mathrm{ON}$ who might arguably be considered as having converted.

It has been suggested that patients with $\mathrm{ON}$ at onset have a more benign course than other MS patients, adding weight to the view that optic nerve involvement implies a biologically different form of demyelination. The relatively benign course of ON appears to be a real phenomenon in the short term, although disability scores gradually approach each other over several years when patients presenting with motor deficits are compared to those presenting with ON. Some of the difference in disability between those with ON or motor deficit at onset may represent an artifact of the scoring system but this does not negate the observation that $\mathrm{ON}$ patients are functionally better for substantial periods of time. It must be remembered, however, that patients with isolated $\mathrm{ON}$ are a select group, since individuals with prior history or findings implying dissemination are excluded. If the implication is that the location of the demyelinating plaque in the optic nerve has something to do with the prognosis, an appropriate control group might be patients who, despite equally careful evaluation, have had only a single episode restricted to the brainstem and have the same disability score at onset.

Studies on $\mathrm{ON}$ currently in progress include laboratory documentation of diagnosis (CSF and evoked responses), and hopefully these will provide greater diagnostic certainty. The abnormalities seen on VER in many patients with demyelinative $O N$ are relatively characteristic. A marked delay in conduction with a normal wave form is not usually seen in other disorders which might resemble $\mathrm{ON}$, (Nikoskelainen et al, 1977; Wilson, 1978; Carroll and Mastaglia, 1979; Halliday et al, 1982).

In summary, we favor the view that isolated demyelinative $\mathrm{ON}$ is a form fruste of MS and agree with Alter that adequately screened $\mathrm{ON}$ cases should be included in MS epidemiologic and family studies (Alter et al 1973). In typical cases the diagnosis remains a clinical one. However, evoked responses and CSF studies are helpful. The presence of oligoclonal banding appears to be of predictive value for the subsequent development of MS (Moulin et al 1983). What to tell patients regarding the risk of MS remains a matter of opinion. We generally tell all patients that symptoms may recur in the eye or elsewhere in the nervous system, and usually inform younger patients, especially those with banding, of the specific implications so that their long-range plans may be made with the possibility of MS in mind.

\section{References}

Alter. M.. Good. J.. and Okihiro. M. (1973). Optic neuritis in orientals and caucasians. Neurology 23:631-639.

Arnason. B. (1973). Optic neuritis and multiple sclerosis. New Engl. J. Med. 289:1 140-1141.

Carroll. W.. Mastaglia. F. (1979). Leber's Optic Neuropathy. A clinical and visual evoked potential study of affected and asymptomatic members of a six gencration family. Brain. 102:559-580.

Cohen. M.. Lessell. S.. and Wolf. P. (1979). A prospective study of the risk of developing multiple sclerosis in uncomplicated optic neuritis. Ncurology 29:208-213.

Compston. D.. Batchelor. J.. Earl, C.. and McDonald. W. (1979). Factors in fluencing the risk of multiple sclerosis developing in paticnts with optic neuritis. Brain 101:495-511.

Ebers, G.C.. Cousin. H.K.. Feasby, T.E. and Paty. D.W. (1981). Optic neuritis in familial MS. Neurology 31:1138-1 142.

Ebers. G.C.. Paty. D.W. (1979). CSF electrophoresis in one thousand patients. Can. J. Neurol. Sci. 7:275-280.

Fcasby. T.E.. Ebers. G.C. (1982). Risk of multiple sclcrosis in isolated optic neuritis. Can. J. Neurol. Sci, 9:2, 269.

Georgi. V.W. (1966). Multiple Sklerose. Pathologisch-Anatomische Befunde Multiple Sklerose BEI Klinisch Nicht Diagnostizierten Krankbeiten. Schwizerische Medizinische Wochenschrift. 20:605-607.

Gilbert. J.. Sadler. M. (1983). Unsuspected multiple sclerosis. Arch. Neurol. (in press).

Halliday. A., Barrett. G. Carroll. W.. Kriss, A. (1982). Problems in defining the normal limits of the visual evoked potential. Clinical applications of Evoked Potentials in Neurology edited by J. Courjon. F. Mauguiere, and M. Revol. Raven Press. New York. 1982. 1-9.

Harding. G. and Crews. S. (1982). The visual evoked potential in hereditiry optic atrophy. Clinical applications of Evoked Potentials in Neurology edited by $\mathrm{J}$. Courjon. F. Mauguiere, and M. Revol. Raven Press. New York, 1982. 21 1.30.

Kahana, E. Alter, M. and Feldman. S. (1976). Optic neuritis in relation to multi ple sclerosis. J. Neurol. 213:87-95.

Kraushar. M.F.. Miller. E.M. (1982). Central scrous choroidopathy misdiagnosed as a manifestation of multiple sclerosis. Ann. of Ophthal. 14 (3):215-218.

Kurland, L., Beebe, G. Kurtzke, J., Nagler, B., Auth, T., Lessell, S., and Nefzger. M. (1966). Studies of the natural history of multiple sclerosis. Acta Neurol. Scand. Suppl. 19:42:157-176.

McAlpine. D.. (1964). The benign form of multiple scicrosis: Results of a long term study. Br. Med. J. 2:1029-32.

Moulin. D.. Paty. D.W.. Ebers. G.C. (1983). The predictive value of CSF electrophoresis in "possible" multiple sclerosis. Brain (in press).

Nikoskelainen. E.. Sogg. R.. Rosenthal. A.. Friberg. T.. Dorfman. L. (1977). The early phase in Leber hereditary optic atrophy. Arch. Ophthal. 95.969-978.

Percy. A., Nobrega, F.. and Kurland. L. (1972). Optic neuritis and multiple sclerosis. Arch. Ophthal. 87:135-139.

Perkin, G.D. and Rose. F.C. (1979). Optic neuritis and its differential diagnosis. Oxford: Oxford University Press.

Poskanzer, D.C.. Prenney, L.B., Sheridan, J.L., and Yon Kondy, J. (1980). Multiple Sclerosis in the Orkney and Shetland Islands. I. Epid clinical factors and methodology. J. Epidemiol. Commun. Health. 34 (4):229-239.

Sandberg-Wollheim, M.. Platz, P.. Ryder. L.. Nielsen. L.. and Thomsen. M. (1975). HL-A histocompatibility antigens in optic neuritis. Acta. Neurol. Scan. 52:161-166.

Wilson. W. (1978). Visual-evoked response differentiation of ischemic optic neuritis from the optic neuritis of Multiple Sclerosis. Amer. J. Ophthal. 86. $530-535$ 